\title{
ASSENTAMENTO E SUSTENTABILIDADE
}

Maria Aparecida Daniel da Silva*

\section{Resumo}

A degradação do meio ambiente tem sido causa de sérias preocupações da comunidade científica, das organizações governamentais e nãogovernamentais. A questão ambiental no Brasil tem suscitado investigações em vários campos científicos, inclusive no das Ciências Sociais, que ainda não a assumiram como prioridade em suas pesquisas. O presente texto faz uma discussão sobre a prática produtiva em assentamentos rurais goianos, ou seja, se suas atividades agrárias estão ou não voltadas para a sustentabilidade. Tal indagação requer um estudo mais aprofundado, pois trata-se de uma questão socioambiental complexa, envolvendo fatores intrínsecos e extrínsecos ao problema, local e globalmente dimensionados. Destaca-se a necessidade de trabalhar o conceito de desenvolvimento sustentável de maneira mais abrangente, ou seja, na perspectiva dos recursos naturais nos assentamentos rurais e do próprio modo de vida - os traços culturais, as crenças, as práticas de trabalho e produção, enfim a vida cotidiana - desses trabalhadores.

Palavras-chave: Assentamento, sustentabilidade.

\section{Introdução}

O presente texto é uma primeira discussão do tema do meu projeto de doutoramento que tem como horizonte a problemática mais ampla da questão agrária brasileira. Sem terra, sem maiores condições para enfrentar o latifúndio, sem assistência dos sucessivos governos e sem meios adequados para produzir, os pequenos produtores rurais vêm

* Professora do Departamento de História e Geografia, Ciências Sociais e Relações Internacionais da Universidade Católica de Goiás.

E-mail: marriap@ig.com.br 
se organizando na luta pela terra, no trabalho e na produção. Os registros históricos e pesquisas acadêmicas demonstram que a biografia desses agentes sociais compreende uma contínua itinerância, ocupando regiões de fronteira, uma após outra. As grandes produções monocultoras, o latifúndio e a especulação imobiliária rural têm implicações diretas na exclusão desses produtores rurais familiares.

Em Goiás, nas últimas duas décadas, a organização desses trabalhadores, principalmente por intermédio da Comissão Pastoral da Terra (CPT), da Federação dos Trabalhadores na Agricultura (Fetaeg) e do Movimento dos Trabalhadores Rurais Sem Terra (MST), tem obtido importantes resultados. Várias famílias já foram assentadas ${ }^{1}$ e já estão produzindo. Cada assentamento é uma realidade diferenciada. Há assentamentos com maiores possibilidades produtivas e comerciais, com mais assistência técnica, mais organização do trabalho do que outros. Mas, de uma maneira geral, todos eles se deparam com dificuldades. Atualmente, um dos maiores desafios enfrentados por esses produtores rurais familiares é o de continuarem se (re)produzindo como categoria social e econômica, sem perderem a sua identidade ou o seu modo próprio de viver. Outro grande desafio, para que se reproduzam como produtores rurais familiares, é criar novas alternativas de trabalho, de produção e comercialização do excedente, sem se subordinarem cegamente ao darwinismo da economia capitalista. Ou seja, sem se transformarem em meros produtores das mercadorias requeridas pelo mercado.

As discussões sobre a necessidade de preservação do meio ambiente $^{2}$ estão cada vez mais freqüientes, e a demanda por produtos não contaminados cresce à medida que aumenta a conscientização dos consumidores. Pessoa (1999, p. 154) afirma que "os assentados que se recusarem a aprender e aplicar novas tecnologias, de maneira sustentável, terão dificuldades de se reproduzirem como agricultores". Pois, como se sabe, são trabalhadores rurais descapitalizados, com pequenas extensões de terra agricultável e parcas condições de mecanização. Isso os coloca numa posição diametralmente oposta à dos grandes produtores extensivos e monocultores.

O horizonte de produção e reprodução dos assentados goianos não está, portanto, na competição pela produtividade, mas sim no desenvolvimento de novas práticas de produção, sem degradar tanto o 
ambiente, produzindo alimentos sem insumos químicos, bastante requeridos hoje pelo mercado. Resta saber se os atuais assentados têm essa consciência e se têm projetos nesse sentido.

\section{A prática produtiva nos assentamentos}

Tomando como base a realidade produtiva de agricultores familiares goianos, em situação de assentamento, é interessante entender os princípios norteadores da sua prática produtiva, especialmente numa perspectiva de sustentabilidade, ou seja, indagando se a organização produtiva dos assentados rurais está procurando romper com a tendência macroeconômica de uma agricultura predominantemente voltada para o mercado, ou se está empenhada na manutenção de formas e saberes produtivos locais, ou, ainda, se se constata uma possibilidade de junção das duas perspectivas.

Entrando na terra tão sonhada, esses assentados buscam recuperar outros valores. Por exemplo, o universo simbólico-cultural, as lembranças e a dignidade que perderam, morando em periferias de cidades, em condições precárias. Recuperar o sentido da vida é fundamental e faz parte do projeto desses trabalhadores, como expressa Pessoa (1999, p. 247): “o movimento camponês ${ }^{3}$ precisa ser entendido como algo muito além da luta pela defesa desesperada de um pedaço de chão, com um documento cartorial".

A primeira dificuldade, após a instalação no assentamento, referese à organização da produção, uma vez que o assentado conta, por via de regra, com a força dos braços e algumas precárias ferramentas. Os recursos públicos, quando existem, são escassos e quase sempre chegam fora do prazo de plantio. Isso, somado à falta de assistência técnica e de condições de escoamento, coloca o seu produto em desvantagem em relação ao que precisa adquirir no comércio.

Produção implica trabalho e relação homem-natureza, especialmente em se tratando de atividades agrárias. É nessa perspectiva que se dá a relação dos assentados com a natureza, mediada cotidianamente pelo trabalho. É essa mediação que garante, inclusive, a posse da terra, como expressa Damázio Rodrigues, do Assentamento Mosquito: 
Eu vejo que a propriedade é uma coisa que a gente constrói. A gente faz uma casa, é a propriedade que eu tenho - uma casa. Se eu consigo um pedaço de terra e eu faço nele uma roça, um pasto, uma cerca, eu passo a ser o proprietário porque eu tive um investimento próprio nele. Aí eu passo a ser dono daquela propriedade que eu beneficiei. Então eu entendo que a propriedade é uma coisa de um trabalho particular que a pessoa praticou. Passa a ser dono porque ele possui com o seu trabalho. (PessoA, 1999, p. 272)

$\mathrm{Na}$ declaração desse assentado, nota-se claramente o seu entendimento do que é ser dono de uma propriedade. O direito à propriedade passa a existir com a mediação do trabalho, bem ao contrário do que defende o capital de base latifundista, que busca assegurá-lo independentemente da sua realidade produtiva.

Para saber se há sustentabilidade ou não na prática produtiva dos assentados rurais goianos e se o conjunto de suas atividades agrárias está direcionado ou não para uma produção sustentável, faz-se necessária uma discussão sobre o meio ambiente, não no sentido de um ambientalismo/ecologismo preservacionista, mas inserido na reprodução ou não da capacidade produtiva da terra e das águas.

Em relação ao trabalho, trata-se de discuti-lo não como uma categoria à parte, mas diretamente relacionada à prática produtiva dos assentados, buscando compreender o seu lugar e o seu valor, ou seja, se o seu valor de uso está subordinado ao valor de troca; se os assentados trabalham apenas para produzir renda ou se, além disso, querem garantir a sobrevivência de um modo de vida. Se a produção nos assentamentos for subordinada ao capital, este se sobreporá também ao trabalho. Partindo dessa lógica de raciocínio, se a produção nos assentamentos não for praticada de maneira sustentável, o trabalho, inevitavelmente, se transforma em mercadoria, valor de troca superior ao valor de uso, subsumindo-se ao capital que, no sistema de mediação de segunda ordem, ${ }^{4}$

degrada o sujeito real da produção, o trabalho, à condição de uma objetividade reificada - um mero 'fator material de produção' subvertendo, desse modo, não só na teoria mas também na prática social mais palpável, a relação real do sujeito/objeto. (ANTUNES, 2001,p. 25) 
A segunda dificuldade, após a constituição de um assentamento, é a desafiadora inserção no mercado, quando há excedente de produção. De um lado os assentados não teriam como fugir à realidade macroestrutural, vivendo à sua revelia. Não sobreviveriam. Por outro lado, o modo de vida tipicamente camponês, especialmente em se tratando de produtores predominantemente para o autoconsumo, confronta-se com a economia capitalista, altamente competitiva.

Produzir para o mercado está se tornando, portanto, um desafio cada vez maior, sobretudo para pequenos sitiantes, para o produtor familiar rural que não tem acesso aos recursos técnico-agrícolas que garantam produtividade. Há ainda um outro componente nessa reflexão. De acordo com Pessoa (1999, p. 176), "a reprodução econômica e social dos assentados passa tanto pela produção de gêneros requeridos pelo mercado quanto pela produção para o autoconsumo". Ou seja, a produção rural familiar deve se preservar como economia de subsistência, ao mesmo tempo, destinada ao mercado. Essa conciliação passa pela via da (re)produção das condições de vida - objetiva e subjetiva ou material e cultural - camponesa.

Sem determinados recursos necessários para produzir, muitos dos assentados percebem que a luta não termina ao entrarem no lote demarcado. O trabalho é árduo, especialmente quando a terra está degradada. Em meio a essas dificuldades, muitos parceleiros desanimam e acabam voltando para a cidade, deixando aparecer o fenômeno da venda do lote, muito explorado pelos inimigos da reforma agrária.

É evidente que essa é uma questão muito ampla, que envolve muitos aspectos - políticos, econômicos, históricos e sociais -, do ponto de vista global. Danificar a natureza não depende somente da "má conduta" de um indivíduo ou de um grupo social. De novo a questão macro - neste caso, o modelo de produção vigente - deve ser levada em conta. "A destruição e/ou precarização da força do trabalho e a degradação crescente do meio ambiente são consequiências da competição e concorrência intercapitais" (ANTUNEs, 2001, p. 26).

Não podemos, entretanto, dissociar desenvolvimento sustentável da questão agrária brasileira. Milhares de trabalhadores rurais, ao longo dos séculos, vêm reagindo - através de movimentos e organizações como o MST e CPT - ao latifúndio devastador e buscando o seu espaço de vida 
no campo. Vale lembrar, como exemplo, a campanha de assinaturas para um Projeto de Emenda Popular, advogando a limitação da propriedade fundiária a 35 módulos rurais regionais.

\section{Os assentados e a ecologia}

São várias as pesquisas acadêmicas envolvendo assentamentos rurais goianos, mas nenhuma se preocupou em investigar se a prática (re)produtiva nesses assentamentos está, ou não, voltada para a sustentabilidade. Esse modo de produção (familiar), conforme Maristela do Carmo, "procura assegurar um nível de vida estável para o conjunto da família e a reprodução dos meios de produção". Explicitando melhor o que é produção familiar, a autora cita Hugues Lamarche, que diz: "a exploração familiar, tal como nós a concebemos, corresponde a uma unidade de produção agrícola onde a propriedade e o trabalho estão intimamente ligados à família" (CARMO, 2001, p. 236).

Parece sem importância pesquisar produção familiar e sustentabilidade num país onde impera o latifúndio degradador da ecologia, ${ }^{5}$ mas não é, e os dados revelam a sua importância. Ainda de acordo com Carmo (2001, p. 238), em 1980, 3,6 milhões ou 70\% dos 5,1 milhões de estabelecimentos rurais existentes no Brasil foram classificados como familiares. A autora completa sua afirmação dizendo que "uma estimativa mais recente faz referência a 6,5 milhões de estabelecimentos rurais familiares, por uma superfície total de 100 milhões de hectares". Se nessas unidades familiares as atividades agrárias forem praticadas de maneira sustentável, sua importância será muito mais que quantitativa, marcando o início de uma nova era de relação com meio ambiente, produzindo e comercializando produtos orgânicos. ${ }^{6}$

Pelo que observei in loco a ação de muitos assentados é contrária à prática produtiva sustentável. Há terras que já se encontravam seriamente devastadas, mesmo antes de serem ocupadas, em função de práticas de uma agricultura à maneira antiga. Práticas que ainda existem, pois muitos parceleiros continuam fazendo queimadas, pescando com redes, caçando animais silvestres, prendendo pássaros em gaiolas, não respeitando a mata ciliar, desmatando para formar pastos, além de outras 
práticas comprometedoras do ecossistema. Essa postura é uma combinação de vários fatores que devem ser aprofundados. Em parte é um legado histórico. As queimadas, por exemplo, já eram feitas no século XIX e foram registradas por viajantes estrangeiros que passaram por Goiás. Outro aspecto a ser considerado é a trajetória do produtor rural familiar. Quem vive na itinerância não cria raiz, não finca os pés no lugar por muito tempo, por isso não cria mecanismos de preservação do solo. Sendo assim, "esses agricultores continuam praticando uma agricultura rústica e predatória” (PessoA, 1999, p. 49). A falta de oportunidades de aprendizado de novas técnicas de produção, entre outros fatores, faz com que continuem apenas esgotando as fontes naturais. É preciso analisar todos esses fatores e contribuir para o rompimento dessa prática produtiva degradadora.

Para se ter uma noção do grau de devastação que vem sofrendo este planeta, vamos a alguns dados, citados por Luna e MacDonald (2000, p. 9): cerca de seis milhões de hectares da superfície da Terra são desertificados a cada ano; dez milhões de hectares de matas úmidas são desmatadas anualmente; o mar já foi muito utilizado como depósito de lixo atômico e só os EUA despejaram 370 mil toneladas de material radioativo no Oceano Pacífico.

No Brasil, a degradação do ambiente vêm se acelerando e pode ser percebida na degradação dos solos, na poluição das águas por agrotóxicos, na redução dos mananciais, em função do desmatamento, do assoreamento e das irrigações. A Mata Atlântica já foi devastada em 93\%; o mesmo acontecendo com 50\% do cerrado e cerca de $14 \%$ da Floresta Amazônica (LunA e MACDonald, 2000, p. 9). Zamberlam e Froncheti (2001, p. 82) dizem mais: "em 1950 o mundo possuía 30\% de florestas. Em 1975, 12\%. No ano de 2000, 7\%".

No caso brasileiro, um dos principais motivos de toda essa agressão à natureza é a sustentação do modelo de produção agroexportador. Esse é um fator de análise relevante para constatar se os assentados (que também degradam o meio ambiente) têm alguma chance de viabilizar sua (re)produção de maneira sustentável - sem esgotar as fontes naturais.

De acordo com Zamberlam e Froncheti (2001, p. 87), 
um processo de desenvolvimento possui sustentabilidade quando por ele se consegue a satisfação das necessidades, sem comprometer o capital natural e sem lesar o direito das gerações futuras de verem atendidas também as suas necessidades e de poderem herdar um planeta sadio com seus ecossistemas preservados.

Nesse sentido, há uma prática produtiva não sustentável (salvo as exceções) nos assentamentos rurais goianos. Conforme a pesquisa de Pessoa (1999, p. 283), apenas 53\% dos parceleiros pensam "ser necessário preservar a natureza, ou seja, explorá-la sem destruí-la”. Mas, segundo o autor, a prática desses assentados não corresponde a essa "vontade", sendo que nem uma terça parte deles cumpre as normas de preservação, recorrendo às queimadas nos pastos e/ou nas palhadas; praticando caça e pesca predatórias; não respeitando a exigência do Código Florestal de preservação de $20 \%$ em vegetação nativa e outros. Porém, não se pode tomar os assentados como os vilões dessa história, pois, "em muitos casos, quando os assentamentos são construídos, as áreas já estão em processo avançado de devastação" (PessoA, 1999, p. 288). Além disso, eles não recebem incentivos nem orientações técnicas de sustentabilidade para que possam romper com as suas práticas agrícolas tradicionais. Por isso, muitos deles até sabem que para haver a continuidade da vida é necessário preservar a natureza, mas o modus operandi $i^{7}$ é contrário.

\section{Agrário/ambiental}

Para Leite Linhares e Silva (1999, p. XIII), a questão agrária é considerada o maior obstáculo econômico, social, político e ético ao desenvolvimento do conjunto do Brasil e, muito especialmente, o óbice ao exercício pleno da cidadania no país. ${ }^{8}$ A questão agrícola está intrinsecamente ligada à questão agrária, apesar de ser conceituada em separado. ${ }^{9} \mathrm{O}$ que se produz, quais os métodos e as técnicas utilizadas não são tarefas desvinculadas do contexto maior e nem alheias ao processo econômico e social.

A política de substituição de importações, iniciada no governo de Getúlio Vargas, na década de 1930 e acentuada na década de 1950 
com a inserção do grande capital externo, mudou o cenário políticoeconômico do país, agravando ainda mais a situação precária na qual já viviam milhões de pequenos produtores rurais. Uma das principais metas do governo Vargas, senão a principal, era desenvolver a indústria a qualquer preço. A produção agrícola fora subordinada à indústria, servindo ao abastecimento do mercado interno e gerando divisas para financiar a industrialização. O sonho de uma vida nova e moderna, para milhares de trabalhadores rurais, passou a ser um emprego na cidade. Assim, muitos saíram em direção aos centros urbanos, resolvendo a demanda de mão-de-obra nas indústrias. As mudanças foram tamanhas que se inverteu completamente a relação campo-cidade,

com a população rural passando de $64 \%$ da população total do país, em 1950, para 33\%, em 1980, enquanto a população urbana passava, em igual período, de $36 \%$ para $67 \%$ do total. De 1980 até 1991, a população rural foi ainda mais reduzida, caindo para $24 \%$ do conjunto da população brasileira. (Leite Linhares e SiLva, 1999, p. 149)

Mais tarde - a partir de meados da década de 1960 -, a agricultura sofreu um processo de transformação capitalista, chamado de modernização conservadora ou de Revolução Verde. ${ }^{10}$ Nesse processo houve muitas mudanças, principalmente em relação às técnicas, à organização da produção e às relações sociais. Essas transformações causaram grande impacto na agricultura familiar. Intensificaram-se os bóias-fria ou trabalhadores volantes (que não têm trabalho fixo). O uso de máquinas e a produção em moldes empresariais tiveram como um de seus principais efeitos a expropriação de pequenos produtores, sendo proprietários ou não de parceiros ou posseiros.

Outra mudança verificada foi em relação ao trabalho, assalariando grande parte da mão-de-obra no campo e, também, na ordem da produção, de subsistência para uma produção destinada ao mercado. A meta dos produtores, em geral, era produzir mercadorias e não produzir alimentos destinados ao mercado interno (Graziano Neto, 1985, p. 26).

A história não é uma sucessão de fatos e nenhuma realidade local é uma "ilha", sobretudo na época em que vivemos - de intensificação da globalização. A questão posta, se os assentados desenvolvem ou não 
suas atividades agrárias de maneira sustentável, ${ }^{11}$ requer atenção aos fatos históricos que implicam suas ações. Nesse contexto a prática produtiva não parte apenas de vontades e/ou decisões internas desses indivíduos, mas também da realidade exterior a eles. Trata-se de analisar os dois lados, o intrínseco e o extrínseco da questão, numa relação dialética. A questão agrária no Brasil, por exemplo, surgiu em um contexto histórico, político e econômico mais abrangente (global), mas que envolve direta ou indiretamente cada cidadão deste país.

Como se vê, o problema da sustentabilidade em assentamentos é constituído de vários elementos interligados e sua compreensão se dará pela análise da relação que há entre macro e micro-história. Ou seja, se a prática produtiva nos assentamentos rurais está ou não direcionada para a sustentabilidade, ela implica ações decisivas, vindas de projetos coletivos e de ações individuais. A compreensão desses projetos e ações passa pelo exercício do conhecimento multidisciplinar. Por se tratar de um fenômeno socioambiental, somente a sociologia não abarca essa compreensão. Necessitamos de conceitos e modelos de análise de outras áreas do conhecimento, especialmente das ciências da natureza.

A área de pesquisa das ciências sociais é vasta, possibilitando a produção e aplicação do conhecimento sociológico em diversas dimensões da vida em sociedade. Um de seus campos de estudo é a interferência, direta e indireta, no meio ambiente e os impactos socioambientais causados pela ação humana.

Nesse sentido, Julia Silva Guivant (1998), faz uma crítica às ciências sociais dizendo que a sociologia rural ainda não assumiu a questão ambiental como prioridade em suas pesquisas. E que a maior parte das denúncias sobre os riscos ao meio ambiente e à saúde da população tem sido feita por profissionais de outras áreas. Diz ainda que, apesar de haver importantes trabalhos criticando o modelo agrícola brasileiro, e fundamentados na perspectiva de uma agricultura sustentável, eles "não chegam a quebrar um certo isolamento da questão referente à sustentabilidade agrícola, nas pesquisas de ciências sociais concernentes ao meio ambiente no Brasil" (GuIvant, 1998, p. 100). Cabe, então, aos cientistas sociais continuarem construindo esse novo paradigma científico, tratando das questões socioambientais com mais afinco, colaborando para que haja maior conscientização e interesse - da academia, dos 
órgãos governamentais e não-governamentais, das comunidades em geral - em salvar o planeta, produzindo alimento e riquezas, mas, ao mesmo tempo, cuidando, recuperando e preservando os recursos naturais, uma vez que eles são finitos e sujeitos a sérias degradações.

\section{Desassistência pública}

Até outubro de 1999, a legislação exigia, como requisito para a instalação de um assentamento, a realização de um estudo, pelo Incra, sobre as potencialidades hídricas e produtivas da área, chamado Plano de Viabilidade Técnica (PVT). Em 4/11/1999, foi promulgada pelo órgão a Portaria no 477 , criando outra modalidade de projeto para viabilizar os assentamentos. É o Projeto de Desenvolvimento Sustentável (PDS) que, de acordo com o Art. 3o, "terá as bases de sustentabilidade e promoção de qualidade de vida como seus pontos determinantes". Analisando unidades instaladas em diferentes períodos será possível saber se houve mudanças no sentido de viabilizar a produção nesses assentamentos. Constatam-se muitas dificuldades para a implantação desses projetos. Os recursos são mínimos e demorados em função da burocracia dos órgãos públicos, há escassez de assistência técnica e fornecimento tardio das sementes para plantio, entre outros embaraços.

Segundo Espinosa (1993), a Comissão Mundial de Meio Ambiente (CMMAD/1987) define desenvolvimento sustentável como aquele que atende às necessidades do presente sem comprometer as possibilidades de as gerações futuras atenderem as suas próprias necessidades. Define conservação ambiental como a gestão racional da utilização da biosfera, de tal sorte que produza o maior benefício sustentável para a humanidade e o crescimento econômico e eqüidade social são tidos como medidas de política econômica e social para satisfazer as necessidades mais urgentes da sociedade e a melhoria da qualidade de vida.

De acordo com a Agenda 21 Brasileira, do Ministério do Meio Ambiente (apud Luna e MACDonald, 2000, p. 15-16), é preciso trabalhar o conceito de sustentabilidade ou de desenvolvimento em várias dimensões, tais como: sustentabilidade ecológica - manter os estoques de capital natural; sustentabilidade ambiental - assegurar a capacidade 
de sustentação dos ecossistemas; sustentabilidade social - para melhoria da qualidade de vida da população, adotar políticas distributivas e/ou redistributivas e a universalização do atendimento na área social; sustentabilidade política - construir a cidadania, incorporar os indivíduos ao processo de desenvolvimento; sustentabilidade econômica administrar eficientemente os recursos em geral e a regularidade dos fluxos do investimento público e privado; sustentabilidade demográfica - cotejar os cenários ou tendências de crescimento econômico com as taxas demográficas; sustentabilidade cultural - manter a diversidade de culturas, valores e práticas no planeta, no país e/ou numa região que compõem ao longo do tempo a identidade dos povos; sustentabilidade institucional - criar e fortalecer engenharias institucionais e/ou instituições que consideram critérios de sustentabilidade; sustentabilidade espacial - buscar a maior eqüidade nas relações inter-regionais; sustentabilidade democrática - avaliar os aspectos da distribuição do poder produtivo e do poder institucionalizado, bem como os aspectos relevantes para a comunidade e para a família.

Todos esses aspectos ambientais, sociais, econômicos, políticos e culturais especificados por Espinosa (1993) e pela Agenda 21 fazem parte do conceito geral de sustentabilidade e devem ser levados em conta nessa discussão. Mas o desenvolvimento sustentável nos assentamentos rurais não deve ser mensurado apenas por esses aspectos, digamos, palpáveis. Um programa de reforma agrária eficaz contempla cada uma dessas dimensões porque todas são importantes, mas a sustentabilidade nos assentamentos precisa ser mais abrangente, numa visão denominada holística, superando a dicotomia entre a sociedade e a natureza.

O campo em discussão não diz respeito a qualquer categoria de trabalhador, mas aos trabalhadores rurais que lutam pela reforma agrária, a qual, se entendida num sentido amplo, preserva o meio ambiente do ponto de vista ecológico - elementos bióticos e abióticos -, mas também respeita e propicia a (re)produção dos diversos grupos sociais, entre eles a categoria produtores rurais familiares (assentados), em todas as suas dimensões - materiais e não materiais.

São trabalhadores rurais que estão lutando, não só por um pedaço de chão, mas querem, segundo análises preliminares, reconstituir seu 
modo de vida, suas festas, suas formas de trabalho, de produção, de crenças e de outros traços da cultura camponesa. De acordo com as constatações de Pessoa (1997), esses trabalhadores em situação de assentamento estão buscando resgatar suas tradições, tais como festas religiosas (Folias de Reis, do Divino, as festas juninas e outras devoções), seus mutirões, suas benzeções e outras práticas religiosas e socioculturais. Nesse sentido, saber se há sustentabilidade é entender até que ponto esses trabalhadores estão tendo condições de se preservar e se (re)produzir como um grupo social específico.

Mesmo com o fenômeno da rurbanidade ${ }^{12}$ e com as novas tecnologias que vêm "alterando as formas de organização do processo de trabalho, reduzindo a escala mínima necessária da atividade econômica e redefinindo a sua localização espacial", ${ }^{13}$ o modo de vida desses trabalhadores rurais assentados não se diluiu completamente.

Não há dúvida de que o fenômeno da urbanização do campo brasileiro, nas duas últimas décadas, tem provocado choque de culturas e problemas de integração social entre as gerações e as diferentes classes sociais, causando grandes disparidades sociais e regionais, mas não ao ponto de descaracterizar por completo o modo de vida do agricultor rural familiar. Resta saber até que ponto eles foram atingidos pela invasão do urbano e se continuarão a luta pela preservação de suas tradições e práticas de existência. As sociedades rurais têm sido consideradas como locais ativos de desenvolvimento e modernidade, mesmo que tardiamente. A influência do urbano sobre o rural é mais acentuada, mas essas duas realidades (campo e cidade) coexistem e se perpassam.

\section{Considerações finais}

Do ponto de vista socioeconômico, já se pode considerar o bastante um desenvolvimento sustentável que atinja os seguintes níveis: econômico, expansão da produção de mercadorias; do meio ambiente, recuperando e preservando os recursos naturais; do desenvolvimento humano, combinando produção de riquezas/mercadorias com a progressiva melhoria da qualidade de vida e incentivando o crescimento do ser humano como um todo. Mas a promoção da sustentabilidade em assentamentos precisa ultrapassar essas dimensões. 
Há definições que ampliam os conceitos de produção e sustentablidade. Por exemplo, que o desenvolvimento, além de sustentável, seja solidário - no sentido de estabelecer relações de produção e distribuição das riquezas produzidas, numa relação de solidariedade -, diferente da lógica do capital, que é baseada na competição e individualismo e na idéia de vencer a qualquer custo. Propõe-se "que as pessoas modifiquem seu comportamento em relação às outras pessoas, ao meio ambiente, ao sistema de produção e consumo, para conquistar efetivamente a qualidade de vida e uma sociedade mais humana" (Eco/Cut, 2000, p. 10). Esta revista de Ecologia da CUT defende ainda que, para isso acontecer, é necessário fomentar projetos que envolvam clubes de troca e empresas autogestoras que se caracterizem por aspectos democráticos. E, ao invés de socialismo, propõe-se o solidarismo (autogestão e cooperativismo).

Além dessas, acrescentamos ainda a dimensão da sustentabilidade (re)produtiva desses trabalhadores assentados. Inseridos numa sociedade abrangente/globalizada e rurbanizada não sobreviverão alheios às transformações socioeconômicas e culturais. Muitos deles buscam recuperar suas tradições, suas crenças, símbolos e práticas produtivas como categoria social específica, apesar de serem influenciados pelos hábitos de vida urbana, por meio dos canais modernos de comunicação e transportes. Mesmo com a influência urbana, introduzindo novos hábitos, transformando o panorama tecnológico rural, urbanizando-o, a agricultura rural familiar não deixa de ser um modo de produção específico.

Um programa de desenvolvimento agrário sustentável deve levar em conta, além da preservação do meio ambiente, a reprodução dos sujeitos envolvidos, como produtores rurais familiares. É nesse aspecto que a sustentabilidade em assentamentos rurais goianos carece ser dimensionada, viabilizando mecanismos para que esses trabalhadores organizem suas atividades agrárias, produzindo e se reproduzindo como uma categoria ou grupo social específico.

\section{Abstract}

The environment degradation has been cause for concern among scientific community, governmental organizations and NGOs. The environment 
subject in Brazil has prompted investigations in several scientific fields, including Social Science, which has not yet taken up this subjects as a priority in its research. This paper aims to start a debate about the productive practice of rural settlements in Goiás, that is to say, whether agrarian activities are directed or not towards sustainability. Such question requires a more profound study, as it is a complex social environmental issue involving facts that are intrinsic and extrinsic to the problem, both from a local to a global perspective. This paper draws the attention to the need to elaborate on the concept of sustainable development in a broader sense. In this perspective, sustainability means to enable the reproduction of natural resources in rural settlements and also in their very lifestyle - cultural features, beliefs, work and production practices. In short, the entire daily life of these workers.

Key words: Settlement, sustainability.

\section{Notas}

1. De acordo com a Divisão de Assentamentos da Superintendência Regional do Incra SR - 4, até o mês de agosto de 2001, já eram 6.770 famílias em 145 assentamentos.

2. Marcos Reigota (1997, p. 14) assim define meio ambiente: lugar determinado ou percebido, onde os elementos naturais e sociais estão em relações dinâmicas e em interação. Essas relações implicam processos de criação cultural e tecnológica e processos históricos e sociais de transformação do meio natural e construído. O Ministério da Educação e do Desporto - MEC (apud SATO, 1997, p. 5) define o ambiente como a complexidade que envolve os aspectos culturais e naturais. Sendo assim, os termos meio ambiente e socioambiental são redundantes. Diz-se apenas ambiente.

3. O camponês é um trabalhador rural cujo produto se destina primordialmente ao sustento da própria família, podendo vender ou não o excedente da colheita, deduzindo a parte do aluguel da terra quando não é proprietário; devido ao destino da produção, é ele sempre policultor (QuEIROZ, 1973, p. 29).

4. “[...] a completa subordinação das necessidades humanas à reprodução do valor de troca - no interesse da auto-realização expansiva do capital - tem sido o traço mais notável do sistema de capital desde sua origem. Neste sistema, o valor de uso é subordinado ao valor de troca; há 'separação e alienação entre o trabalhador e os meios de produção', ou seja, quem produz nem sempre é quem controla. Enfim, a expansão do capital se sobrepõe ao indivíduo e à natureza. No 'sistema de mediação de primeira ordem', a 'finalidade é a preservação das funções vitais da reprodução individual e social' [...]; os seres humanos são parte da natureza, devendo realizar suas necessidades elementares por meio do constante intercâmbio com a própria natureza" (ANTUNES, 2001, p. 19 e p. 22). 
5. De acordo com Boff (1994, p. 18, apud Zamberlam e Froncheti, 2001, p. 79), "Ecologia abrange, além da natureza (ecologia natural), a cultura e a sociedade humana (ecologia humana e social), pois tudo se relaciona com tudo e em todos os pontos". Segundo Michèle Sato (1997, p. 2), a ecologia abarca alguns ecossistemas: o natural (predomínio dos componentes biológicos); o seminatural (com pouca ou muita influência do ser humano) e o antropogênico (com origem no homem - depende do gerenciamento humano).

6. Zamberlam e Froncheti (2001, p. 90) definem agricultura orgânica como a "que evita, ou exclui amplamente, o uso de fertilizantes, pesticidas, reguladores de crescimento e aditivos para a alimentação animal; utiliza leguminosas, adubação verde, lixo orgânico de fora da fazenda, cultivo mecânico, rochas ricas em minerais e modos de controlar insetos, ervas daninhas e outras pragas". De acordo com Guivant (1998, p. 110), há diferenciação de conceitos entre a agricultura orgânica e a agricultura sustentável. A primeira é a agricultura de insumos reduzidos, por isso ainda não completamente sustentável. A segunda, que é chamada, também, de regenerativa, biológica, orgânica, ecológica, entre outros, exclui totalmente o uso de insumos, sendo assim sustentável.

7. Trata-se da teoria como um modus operandi que orienta e organiza praticamente a prática científica (Bourdieu, 1989, p. 60).

8. Mais adiante, os autores (LeIte Linhares e SilVA, 1999, p. XVII) completam o pensamento dizendo: "[...] a questão agrária, entendida aqui como o conflito em torno da extensão plena da cidadania - política e social - aos homens e mulheres que trabalham no campo. Assim, a história da questão agrária surge, entre nós, como um longo processo - entranhado em nossas origens - pela busca de mais igualdade e liberdade”.

9. “A questão agrícola diz respeito aos aspectos ligados às mudanças na produção em si mesma: o que se produz, onde se produz e quanto se produz. Já a questão agrária está ligada às transformações relações de produção: como se produz, de que forma se produz. No equacionamento da questão agrícola, as variáveis importantes são as qualidades e os preços dos bens produzidos. Os principais indicadores da questão agrária são outros: a maneira como se organiza o trabalho e a produção; o nível de renda e emprego dos trabalhadores rurais; a produtividade das pessoas ocupadas no campo etc." (Graziano Neto, 1985, p. 44).

10. Revolução Verde é, na verdade, a penetração capitalista no campo, tendo como objetivo a maximização produtiva que objetivamente usa a natureza para a "maximização dos lucros", sem se preocupar com os efeitos da tecnologia empregada sobre o meio ambiente circundante (ZAMBERLAM e FronCHETI, 2001, p. 14).

11. Produção sustentável é aqui compreendida como uma produção "capaz de satisfazer as necessidades das gerações presentes sem comprometer a qualidade de vida das gerações futuras", ou seja, não degradando os recursos naturais nem "sacrificando as condições vitais de sobrevivência socioeconômica de gerações futuras" (CAMPOS, 1999, p. 330). 
12. Rurbanidade $=$ termo utilizado no $19^{\circ}$ Congresso Europeu de Sociologia Rural, em Dijon (França), de 3 a 7 de setembro de 2001 para designar a invasão do rural pelo urbano ou a urbanização do meio rural. O Congresso discutiu as relações da sociologia rural com a natureza e a tecnologia, no intuito de contribuir para um profundo questionamento da clássica distinção entre cidade e campo, a modernidade e a tradição, que entende as dinâmicas rurais sociais como formada somente pelo urbano (Congress of the European Society for Rural Sociology, 2001, p. 1-3).

13. Ver Graziano da Silva (1997, p. 45).

\section{Referências}

Antunes, Ricardo. Os sentidos do trabalho: ensaio sobre a afirmação e a negação do trabalho. 4.ed. São Paulo: Boitempo Editorial, 2001.

Bourdieu, Pierre. A genese dos conceitos de habitus e de campo. $O$ poder simbólico. Lisboa: Difel, 1989. p. 59-73.

. Esboço de uma teoria da prática. In: Ortiz, Renato (Org.). Pierre Bourdieu. São Paulo: Ática, 1983, p. 46-81. Grandes Cientistas Sociais. CAmpos, Ginez Leopoldo R. de. Agricultura familiar, gerenciamento ambiental e agroecologia: algumas questões provocativas a serem pesquisadas. In: Tedesco, João Carlos. Agricultura familiar: realidades e perspectivas. 2.ed. Passo Fundo: Edupf, 1999.

CARmo, Maristela Simões do. La production familiale comme locus idéal de l'agriculture durable. In: Zanoni, Magda; Lamarche, Hugues (Orgs.). Agriculture et ruralité au Brésil: un autre modèle de développement. Paris: Éditions Karthala, 2001.

CONGRESS OF THE EUROPEAN SOCIETY FOR RURAL SOCIOLOGY, 19, 2001. DIJON. Anais... Disponível em: <http://cc.joensuu.ti/ alma/esrs/arc/ 19calpa.htm>. Acesso em: 20 nov. 2001.

ECO/CUT, Aprender e transformar em d.s.s. (desenvolvimento sustentável solidário), Goiânia: Escola Centro Oeste de Formação Sindical da CUT, 2000 .

Espinosa, H. R. M. Desenvolvimento e meio ambiente sob nova ótica. Revista Ambiente. v. 7, n. 1, 1993.

Graziano da Silva, José. O novo rural brasileiro. Nova Economia, Belo Horizonte, v. 7, n. 1, p. 43-81, maio 1997. 
Graziano Neto, Francisco. Questão agrária e ecologia: crítica da moderna agricultura. 2.ed. São Paulo: Brasiliense, 1985.

Guivant, Julia S. A agricultura sustentável na perspectiva das ciências sociais. In: Viola, Eduardo J. et al. Meio ambiente, desenvolvimento e cidadania: desafios para as Ciências Sociais. 2.ed. São Paulo: Cortez, Florianópolis: Ed. UFSC, 1998.

Leite Linhares, Maria Yedda; Silva, Francisco Carlos Teixeira da. Terra prometida: uma história da questão agrária no Brasil. Rio de Janeiro: Campus, 1999.

Luna, Roberto Lopes de; MacDonald, José Brendan. Em busca de um desenvolvimento sustentável solidário. ECO/CUT, Goiânia: Escola CentroOeste de Formação Sindical da CUT, p. 7-17, 2000.

Ortiz, Renato. Introdução. In: Ortiz, Renato (Org.). Pierre Bourdieu. São Paulo: Ática, 1983. p. 7-36. (Grandes Cientistas Sociais).

Pessoa, Jadir de Morais. A revanche camponesa. Goiânia: Editora da UFG, 1999.

. Cotidiano e história: para falar de camponeses ocupantes. Goiânia: Editora da UFG, 1997.

Movimentos sociais e educação: testando um outro conceito. Estudos: Revista da Universidade Católica de Goiás, Goiânia, v. 27, n. 4. p. 785-800, 2000.

QueIroz, Maria Isaura Pereira de. O campesinato brasileiro. 2.ed. Petrópolis: Vozes, 1976. (Coleção Estudos Brasileiros).

Reigota, Marcos. Meio ambiente e representação social. 2.ed. São Paulo: Cortez, 1997.

SATo, Michèle. Educação para o ambiente amazônico. 1997. Tese (Doutorado) - Programa de Pós-Graduação em Ecologia e Recursos Naturais, do Centro de Ciências Biológicas e da Saúde da Universidade Federal de São Carlos.

Silva, Maria Aparecida Daniel da. Terra "sem lei, nem rei”: Goiás (1822-1850). 2000. Dissertação (Mestrado) - Programa de PósGraduação em História das Sociedades Agrárias da UFG, Goiânia. 
Wanderley, Maria de Nazaré B. Raízes históricas do campesinato brasileiro. In: TEDESCO, João Carlos. Agricultura familiar: realidades e perspectivas. 2.ed. Passo Fundo: Edupf, 1999.

ZAMBERLAM, Jurandir; FRONCHETI, Alceu. Agricultura ecológica: preservação do pequeno agricultor e do meio ambiente. Petrópolis: Vozes, 2001. 
